\title{
Vialoperidol, Mental Retardation, Extrapyramidal Symptoms: The Tricky Trio
}

Vijay Shanmugam G, Ramesh AN, Ammu Thulaseedharan', Kiran G Kulirankal

From the Department of General Medicine and Department of Psychiatry', Pondicherry Institute of Medical Sciences, Ganapthychettikulam, Kalapet, Pondicherry.

\section{Abstract:}

Extrapyramidal symptoms comprise a group of movement disorders of dystonia, akathesia, tardative dyskinesia and parkinsonism. Drug induced extrapyramidal symptoms are known for decades yet the use of these drugs still prevail with the adverse effect skipped or looked over. Presenting a case of an eighteen year old male hailing from a low socioeconomic status brought with complaints of fever and was diagnosed to have meningitis. He was sedated with one stat dose of haloperidol for MRI brain, following which he developed acute dystonic reaction that was relieved after prompt treatment. This case illustrates the affluence with which extrapyramidal side effects following treatment with haloperidol, which may be ridiculed in complicated medical cases.

Key words: Parkinsonian Disorders, Delusions, Delirium, Dystonia, Brain, Meningitis.

\section{Introduction}

Haloperidol is a psychotropic drug of the Butyrophenone family and is used for both chronic and short-term therapy. It is one of the drugs commonly used in delusions, delirium and agitation [1]. It happens to be one of the commonest sedative and antipsychotic drugs used in India. Though the benefits of the drug overweigh the adverse reactions, it is advisable to use this drug with caution in the general population and mental retardation.

\section{Case Report}

An eighteen year old male hailing from low socioeconomic status presented to our casualty with history of fever and altered sensorium. His physical examination revealed neck stiffness and his Kernig's and Brudzinki's signs were positive. Meningitis protocol was followed. Both blood and urine culture were taken and patient was started on injection ceftriaxone $2 \mathrm{gm}$ on twice daily basis. Tablet doxycycline was also added empirically in view of the prevalence of rickettsia infection commonly seen in this locality. Workup for tropical diseases like malaria, dengue was sent and was negative. In addition to the above mentioned tropical diseases $\lg M$ for scrub typhus was sent which later came as positive. His initial labs revealed normal counts with elevated liver enzymes [Table 1]. A cerebrospinal fluid (CSF) analysis was done subsequently which showed lymphocytic predominance and adenosine

Corresponding Author: Dr. Vijay Shanmugam. G

Email: gvijais85@gmail.com

Received: June 27, 2014 | Accepted: July 17, 2014 | Published Online: August 15, 2014

This is an Open Access article distributed under the terms of the Creative Commons Attribution License (creativecommons.org/licenses/by/3.0)

Conflict of interest: None declared | Source of funding: Nil | DOl: http://dx.doi.org/10.17659/01.2014.0076 
deaminase (ADA) was not suggestive of tuberculosis [Table 2].

On day two of admission, patient's fever subsided and his sensorium improved. However, his word fluency and output was slow and reduced with

TABLE 1: Routine labs

\begin{tabular}{|lll|}
\hline LABS & VALUES & NORMAL \\
Hemoglobin & $13.2 \mathrm{~g} / \mathrm{dL}$ & $12-15 \mathrm{~g} / \mathrm{dL}$ \\
Total counts & 4200 & $4000-11000$ \\
Neutrophil & $52 \%$ & $40-75 \%$ \\
Lymphocyte & $44 \%$ & $20-40 \%$ \\
Eosinophil & $2 \%$ & $1-6 \%$ \\
Monocyte & $2 \%$ & $2-10 \%$ \\
Platelet & 2.0 & $1.5-4.5 \mathrm{lakh} / \mathrm{c} . \mathrm{mm}$ \\
Sodium & $138 \mathrm{meq} / \mathrm{L}$ & $135-145 \mathrm{meq} / \mathrm{L}$ \\
Potassium & $4.4 \mathrm{meq} / \mathrm{L}$ & $3.5-4.5 \mathrm{meq} / \mathrm{L}$ \\
Chloride & $97 \mathrm{meq} / \mathrm{L}$ & $95-108 \mathrm{meq} / \mathrm{L}$ \\
Bicarbonate & $23 \mathrm{mmol} / \mathrm{L}$ & $21-29 \mathrm{mmol} / \mathrm{L}$ \\
Smear for malaria & Negative & \\
Dengue NS1/lgM & Negative & \\
Leprtospira lgM & Negative & \\
Scrub typhus IgM & Positive & \\
Total bilirubin & 1.0 & $0.1-1.0 \mathrm{~g} / \mathrm{dL}$ \\
Direct bilirubin & 0.6 & \\
Indirect bilirubin & 0.8 & \\
AST & $421 \mathrm{U} / \mathrm{L}$ & Upto $41 \mathrm{U} / \mathrm{L}$ \\
ALT & $173 \mathrm{U} / \mathrm{L}$ & Upto $41 \mathrm{U} / \mathrm{L}$ \\
GGT & 40 & $9-48 \mathrm{U} / \mathrm{L}$ \\
ALP & $75 \mathrm{U} / \mathrm{L}$ & Upto $56 \mathrm{U} / \mathrm{L}$ \\
Blood culture & No growth & \\
Urine culture & No growth & \\
Creatinine kinase & $253 \mathrm{U} / \mathrm{L}$ & $<17 \mathrm{U} / \mathrm{L}$ \\
\hline & & \\
& & \\
\hline
\end{tabular}

TABLE 2: CSF analysis

\begin{tabular}{|lll|}
\hline LABS & VALUES & NORMAL \\
Color & Transparent & \\
Appearance & Clear & \\
RBC & 2 & Nil \\
WBC & 20 & $0-6$ \\
Neutrophil & $3 \%$ & \\
Lymphocytes & $97 \%$ & \\
Adenosine de-aminase & $8 \mathrm{U} / \mathrm{L}$ & $10 \mathrm{U} / \mathrm{L}$ \\
Glucose & $40 \mathrm{mg} / \mathrm{dL}$ & $40-85 \mathrm{mg} / \mathrm{dL}$ \\
Protein & $45 \mathrm{mg} / \mathrm{dL}$ & $15-45 \mathrm{mg} / \mathrm{dL}$ \\
\hline
\end{tabular}

other nervous system findings being normal. Patient also exhibited another new symptom of increased dependency and attachment towards his parents and was restless in their absence. This was concurred by the patient's parents, which according to them was a new symptom post-illness. This symptom was taken for the recovery phase and patient was kept on close observation. On day three of admission the symptoms persisted and hence the possibility of encephalitis was sought and an MRI brain was planned. A stat dose of injection haloperidol 2.5 $\mathrm{mg}$ was administered for the restlessness, as patient was agitated during MRI. The MRI brain was clean and was not suggestive of encephalitis. On the very same evening patient developed cervical dystonia with head turned towards left with severe pain. There was no gaze preference and the patient was obeying commands. A creatinine kinase (CK) was sent suspecting drug induced extrapyramidal syndrome and was found to be elevated [Table 2]. A stat dose of promethazine 12.5 was administered and the symptoms resolved eventually.

The symptoms persisted on day four of admission and a psychiatry evaluation was planned in view ICU psychosis. The psychiatry evaluation revealed mental retardation with IQ score of 65. A detailed past history revealed delayed developmental milestones, and history suggestive of mental retardation in the father. Further history from the first-degree relatives and peers were consistent with mental retardation. The patient stayed in the hospital for a period of seven days for observation of onset of new symptoms but was uneventful and hence discharged. Though haloperidol induced extrapyramidal symptoms is known, the presence of mental retardation in our patient increased the chance of this dreadful yet preventable adverse reaction. This case accentuates careful vigilance regarding the use of haloperidol and emphasizes the lost art of detailed history taking in patients. 


\section{Discussion}

Haloperidol is one of the common drugs used in day today medical practice for agitation due to its less toxic potential. However, previous studies have indicated serious adverse reactions affecting various systems namely hematopoiesis, respiratory system and cardiovascular system [2-5]. Haloperidol has been used in management of critically ill patient in terms of weaning from mechanical ventilation $[6,7]$. Unlike the general perception that haloperidol is a safe, previous studies conducted by Riker et al. and Seneff et al. have shown QT prolongation among patients on long term haloperidol $[8,9]$. The reason for increased adverse reactions of haloperidol in critically ill patients may be attributed to its metabolism by cytochrome $\mathrm{P} 450$ as it may be compromised during sepsis $[10,11]$.

Extrapyramidal syndrome (EPS) is defined as the adverse effects of neuroleptic drugs that include hyperkinetic (akathisia, acute dystonia, and acute dyskinesia), and hypokinetic Parkinson like symptoms (e.g. bradykinesia, rigidity, and tremor) by Muscettola et al. [12]. A study by Batemen etal. in UK population concluded that extrapyramidal reactions related to haloperidol (predominantly dystonia-dyskinesia) occurred within the first 3 days of treatment and the highest incidence was in younger patients, especially under 20 years of age concurring with other retrospective studies that younger age appears to be an increased risk factor for the development of haloperidol induced EPS [13-15]. Our patient developed EPS within the first twenty four hours, owing to the predisposing conditions like mental retardation and sepsis. The age factor of our patient could have also attributed to the early occurrence of EPS. A prospective study by Rosebush et al. concluded that more than 50\% of the population ended up with EPS when treated with a low average dose of $3.7 \mathrm{mg}$ of haloperidol [16]. A study by Schillevoort et al. on 424 patients on first time haloperidol revealed an incidence of
$13.3 \%$ of EPS [17]. Ramaekers et al. recruited twenty one volunteers aged 18 to 35 years without any significant past medical or psychiatric history and demonstrated that approximately $65 \%$ of the volunteers experienced EPS requiring anticholinergic medication during the first five days [18].

Delayed extrapyramidal manifestations have also been noted by Anderson et al. where a patient developed akathisia 5 days after and dysphoria 6 weeks after receiving a single haloperidol dose of $5 \mathrm{mg}$ [19]. This has been attributed to the increased half-life of 17 to 18 hours of haloperidol [20]. Patients who have experienced drug induced EPS are more prone to develop the same if the same drug is given to the patient again $[11,21]$.

Haloperidol is a commonly used drug and is in clinical use for decades, however the risk benefit ratio is of query. Our case demonstrates one of the dreadful effects of haloperidol, which was accompanied by the ghastly duo of mental retardation and meningitis, thus making the tricky trio a challenging case to treat and an interesting one. Further this case reiterates the need for proper and detailed history taking and should impart a caution when using haloperidol in patients for sedation.

\section{References}

1. Sigma Pharmaceuticals Pty Ltd. Product Monograph. 2003.

2. Abdullah N, Voronovitch L, Taylor S, Lippmann S. Olanzapine and haloperidol: potential for neutropenia? Psychosomatics 2003;44:83-84.

3. Mahutte CK, Nakasato SK, Light RW. Haloperidol and sudden death due to pulmonary edema. Arch Intern Med 1982;142:1951-1952.

4. Sethna R, Notkin R. Haloperidol-induced bronchospasm. Can J Psychiatry 1991;36:525526. 
5. Sato T, Takeichi M. Drug-induced pneumonitis associated with haloperidol. A case report. Gen Hosp Psychiatry 1990;1 2:341-343.

6. Fish DN. Treatment of delirium in the critically ill patient. Clin Pharm 1991; 0:456-466.

7. Moulaert P. Treatment of acute nonspecific delirium with i.v. Haloperidol in surgical intensive care patients. Acta Anaesthesiol Belg 1989;40:183-186.

8. Riker RR, Fraser GL, Cox PM. Continuous infusion of haloperidol controls agitation in critically ill patients. Crit Care Med 1994;22:433-440.

9. Seneff MG, Mathews RA. Use of haloperidol infusions to control delirium in critically ill adults. Ann Pharmacother 1995;29:690-693.

10. Jacob $A$, Zhou $M, W u R$, Wang $P$. The role of hepatic cytochrome P-450 in sepsis. Int J Clin Exp Med 2009;2(3):203-211.

11. Alvarez GF, Skowronski GA. Remember the Side Effects of Haloperidol: A Case Report. Critical Care and Resuscitation 2003;5:266-269.

12. Muscettola G, Barbato G, Pampallona $S$, Casiello M, Bollini P. Extrapyramidal syndromes in neuroleptic- treated patients: prevalence, risk factors, and association with tardive dyskinesia. J Clin Psychopharmacol 1999; 19:203-208.

13. Bateman DN, Rawlins MD, Simpson JM. Extrapyramidal reactions to prochlorperazine and haloperidol in the United Kingdom. Q J Med 1986;59:549-556.

14. Addonizio G, Alexopoulos GS. Drug-induced dystonia in young and elderly patients. Am J
Psychiatry 1988; 145:869-871.

15. Miller $\mathrm{CH}$, Hummer $\mathrm{M}$, Oberbauer $\mathrm{H}$, Kurzthaler I, DeCol C, Fleischhacker WW. Risk factors for the development of neuroleptic induced akathisia. Eur Neuropsychopharmacol 1997;7:51-55.

16. Rosebush PI, Mazurek MF. Neurologic side effects in neuroleptic-naive patients treated with haloperidol or risperidone. Neurology 1999;52:782-785.

17. Schillevoort I, de Boer A, Herings RM, Roos RA, Jansen PA, Leufkens HG. Risk of extrapyramidal syndromes with haloperidol, risperidone, or olanzapine. Ann Pharmacother 2001;35:15171522.

18. Ramaekers JG, Louwerens JW, Muntjewerff ND, Milius $H$, de Bie A, Rosenzweig $P$, et al. Psychomotor, Cognitive, extrapyramidal, and affective functions of healthy volunteers during treatment with an atypical (amisulpride) and a classic (haloperidol) antipsychotic. J Clin Psychopharmacol 1999; 19:209-221.

19. Anderson BG, Reker D, Cooper TB. Prolonged adverse effects of haloperidol in normal subjects. N Engl J Med 1981;305:643-644.

20. Froemming JS, Lam YW, Jann MW, Davis CM. Pharmacokinetics of haloperidol. Clin Pharmacokinet 1989; 17:396-423.

21. Keepers GA, Casey DE. Use of neurolepticinduced extrapyramidal symptoms to predict future vulnerability to side effects. Am J Psychiatry $1991 ; 1$ 48:85-89. 